Article

\title{
The Role of Psychological Capital in Athletic Performance and Career Development of Adolescent Baseball Players in Taiwan
}

\author{
Chih-Pin Lai ${ }^{1}$, Huey-Hong Hsieh ${ }^{2}{ }^{\mathbb{D}}$, Chia-Ming Chang ${ }^{3, *}$ and Fu-Te $\mathrm{Ni}^{3}$ \\ 1 Physical Education and Arts School, Chengyi University College, Jimei University, Xiamen 361023, China; \\ yuehlidoctor@yahoo.com.tw \\ 2 Department of Leisure Management, Taiwan Shoufu University, Tainan 72153, Taiwan; \\ nancylin809@gmail.com \\ 3 Department of Physical Education, Health \& Recreation, National Chiayi University, Chiayi 62103, Taiwan; \\ michi0725@hotmail.com \\ * Correspondence: gr5166@yahoo.com.tw or gr5166@mail.ncyu.edu.tw; Tel.: +886-886-9-12994703
}

Received: 14 July 2020; Accepted: 14 September 2020; Published: 16 September 2020

\begin{abstract}
Although many baseball players dream of playing professionally, intense training together with psychological pressure and injuries may increase athletes' burnout and may lead athletes to quit and pursue alternate careers. Therefore, it is important for athletes to manage their mental toughness on their career paths. Findings from previous psychological capital (PsyCap) studies suggested that PsyCap had a positive influence on stress reduction. Therefore, this study examined PsyCap's effects on athletes' performance and career development, particularly under stress. We hope the findings can provide useful suggestions for athletes and coaches. To explore the relationships of PsyCap with athletic performance and career development, a structured questionnaire was distributed to 800 baseball players enrolled in middle and high schools in Taiwan with a valid return rate of $80.9 \%$. Confirmatory factor analysis was used to verify the relationships among PsyCap, performance, and career development. The findings showed that PsyCap had significant influence on both athletic performance and career development of the study subjects. Based on our findings, implications for baseball players and coaches as well as suggestions for future research are discussed.
\end{abstract}

Keywords: baseball players; psychological capital; player performance; career development

\section{Introduction}

Baseball is considered a national sport in Taiwan, and there is no double that this sport draws a lot of attention from the public. Every time when Taiwan's national baseball team plays at any international competition, people are brought together as viewers gathering around TV cheering on the team. In fact, Taiwan's national baseball team has seen success in many competitions. Junior league players, in particular, have won so many games and through the television broadcasting these players successfully market Taiwan to every corner of the world [1].

Becoming a professional baseball player does not happen overnight, but takes years of training, conditioning, discipline, determination, skill, and talent. While these training programs are usually designed to build players' agility, explosive power, strength, endurance, and skill, it is the mental quality that makes the player stand out [2-4]. According to sport psychologists, mental toughness is the quality to distinguish the winner from other competitors and mentally tough players often have a better chance of winning a highly competitive event [5].

Psychological capital (PsyCap) has been applied in evaluating individuals' psychological quality under stress, anxiety, and challenge. PsyCap is defined as the positive state of an individual dealing 
with a challenge, and with his positive psychological resources, he develops a positive mental state for success [6]. In other words, a player with positive PsyCap is self-confident and believes that he is capable of handling pressure with ease. However, without such mental toughness a player experiences anxiety, depression, and uncertainty, and can totally lose his natural self-confidence $[7,8]$. Research showed that PsyCap affects an individual's work performance $[9,10]$ and can be used to assess an employee's job performance [11].

In addition to player's performance, career development is another major emphasis of the current study. Career development is a lifelong process of managing work and role play, and is deeply influenced by self-concept, psychological, physical, and social factors. Career development includes career choice and career adaptability [12]. There is no doubt that every athlete is concerned about his/her career planning. Young players with great performance either join the professional team continuing their baseball career with high pay, or join the international team to compete with the world's best players [13]. However, career choices for average players are limited. They either play in an amateur team or become a team coach. Repeated injuries may also force them to reconsider if baseball can still be one of their future career options [14].

A recent study examined team coaching and cohesion in the context of a player's PsyCap, as well as how PsyCap could contribute to the likelihood of player burnout [2]. The results of this study indicated that PsyCap is indeed an important factor in determining the success of baseball players and avoidance of burnout. In addition, PsyCap can affect athletic performance, particularly during the stress of competition. Poor performance may lead to burnout and affect the career development of athletes. As such, knowledge about how PsyCap is related to athletic performance and the career development of athletes could assist athletes and coaches in designing training and development strategies to enhance performance and career development. Since adolescence is a crucial period for athletic career development, in this study we examined the effects of PsyCap on performance and career development of high school baseball players. The following will develop the research hypotheses based on research purposes and literature.

\subsection{Theory of Psychological Capital (PsyCap)}

Luthans et al. [7] proposed that positive organization behavior theory could be combined with positive psychology in a concept termed PsyCap, which comprises four components: self-efficacy, hope, optimism, and resilience. Self-efficacy is related to how an individual believes that his or her capacity to execute behaviors is sufficient to attain specific performance levels [14-16]. Confidence in one's ability to control their own motivation, behavior, and social environment also affects self-efficacy [17]. According to Snyder et al. [18], hope is defined as a positive attitude that is reinforced by interactions among success, strategies, and determination. People who have higher levels of hope are more likely to establish clear goals and manage multiple pathways toward achieving these goals, even in the face of obstacles. Optimism is defined as a tendency to believe that one's life experiences are more likely to be positive [19]. Optimists are also more likely to view outcomes of future events in a positive light and maintain a positive mental state. Resilience refers to the ability of an individual to recover from unpleasant experiences [20].

\subsection{The Relationship between Psychological Capital (PsyCap) and Player Performance}

Several studies indicated that people with higher psychological capital (PsyCap) could have positive influences on individuals and organizations [9,10]. Peterson et al. [8] examined the relationship between PsyCap and employee performance in a financial service company using a latent growth modeling approach. They showed that the PsyCap of 179 consultants enrolled in the study increased over time, concurrent with improvements in performance.

For self-efficacy and resilience, $\mathrm{Ni}$ et al. [21] investigated 286 college badminton players and found that among the four PsyCap components, self-efficacy and resilience, in particular, were significantly positively correlated with sport achievement. Lee et al. [22] investigated the links among PsyCap 
and performance of wrestler athletes, and particularly how they were affected by self-efficacy, hope, optimism, and resilience. They showed that student athletes who had higher self-efficacy, hope, optimism, and resilience tended to have better athletic performance. In addition, they concluded that hope was a better predictor of athletic outcomes than self-esteem and confidence. In an investigation of 192 competitive student athletes, Chen and Chi [23] also showed that student athletes who had a positive mindset associated with hope had superior stress-coping strategies compared to those having lower degrees of hope. Hsieh and Yeh [24] examined 1275 college students in Taiwan and found that optimism was positively correlated with self-efficacy and sport performance. Meanwhile, Huang [25] reported that mentally tough athletes showed higher levels psychological resilience when coping with challenges and physical limits compared to average athletes.

Drawing from these previous studies, we propose the following research hypotheses:

Hypothese 1 (H1). Self-efficacy has positive influences on performance.

Hypothesis 2 (H2). Hope has positive influences on performance.

Hypothesis 3 (H3). Optimism has positive influences on performance.

Hypothesis 4 (H4). Resilience has positive influences on performance.

\subsection{The Relationship between PsyCap and Career Development}

Locke and Latham [26] concluded that individuals who have higher self-efficacy were more likely to set and achieve high goals, and to attempt more difficult tasks. Similarly, Yu et al. [27] demonstrated that employees who had higher self-efficacy performed better during difficult times. When facing difficulties, these individuals would analyze situations, maintain composure, and outperform those who had lower levels of self-efficacy. Other studies showed that employees with higher self-efficacy were more likely to think that they were capable of achieving goals, stay positive when facing challenges, and select optimal pathways to achieve goals, which together contributed to a greater likelihood of their maintaining a given career path. According to Niles and Sowa [28], individuals having low self-efficacy would be more likely to be anxious about career development, and would also feel threatened by challenges faced in the workplace. Those individuals who had high self-efficacy were more likely to make investments in their careers by setting goals, solving problems, collecting career information, and taking adequate actions [29]. Curry and Snyder [30] suggested that athletes with high hope persist when faced with obstacles. Such athletes were willing to face challenges directly and always maintain a positive attitude. Snyder [31] proposed that hope creates positive moods and attitudes that channel individuals toward the appropriate pathways (strategies) to reach goals. Scheier and Carver [32] indicated that positive moods can alter the thinking and behavior of an individual to make them more creative and innovative. Positive moods also enhance the physical, mental, social, and psychological well-being of individuals, and together can increase the competence of employees. Optimistic individuals expect good things to happen and that things are attainable. As a result, they are more likely to persist and persevere in pursuit of their goals [32]. Meanwhile, Lin [33] noted that psychological resilience is a mechanism to cope with stress that has psychological, emotional, and physical dimensions. Psychological resilience refers to the ability of an individual to properly adapt to stress and adversity. Loehr [34] stated that athletes who have strong psychological resilience are more energetic, relaxed, and composed when faced with difficulty compared to those having less resilience.

Together the results of these studies suggested that PsyCap could help athletes boost their confidence and maintain an optimistic outlook. For young baseball players, these psychological traits could influence decisions they make about their athletic careers. In light of these findings, we propose the following research hypotheses: 
Hypothesis 5 (H5). Self-efficacy has positive influences on players' career development.

Hypothesis 6 (H6). Hope has positive influences on players' career development.

Hypothesis 7 (H7). Optimism has positive influences on players' career development.

Hypothesis 8 (H8). Resilience has positive influences on players' career development.

\subsection{The Relationship between Player Performance and Career Development}

The sports industry in the Western world is far more established than that in the East [35]. In Taiwan, career opportunities in sports industries are limited. Professional athletes who lack skills outside of sports often experience challenges in finding employment after retirement from sports. Young athletes often have very limited career choices [36]. The lack of strong support from schools (e.g., coaching, sufficient athletic facilities, adequate internal/external funding sources) can negatively affect the athletic performance of young baseball players who in turn could have few career options [37]. In contrast, young players who have superior athletic performance not only enjoy multiple educational opportunities, but also have more opportunities to participate in sanctioned athletic games. These athletes have a broader range of career choices. Based on these findings, we formulated the following research hypothesis:

Hypothesis 9 (H9). Player s' performance has positive influences on career development.

Figure 1 presents the framework of the research hypotheses.

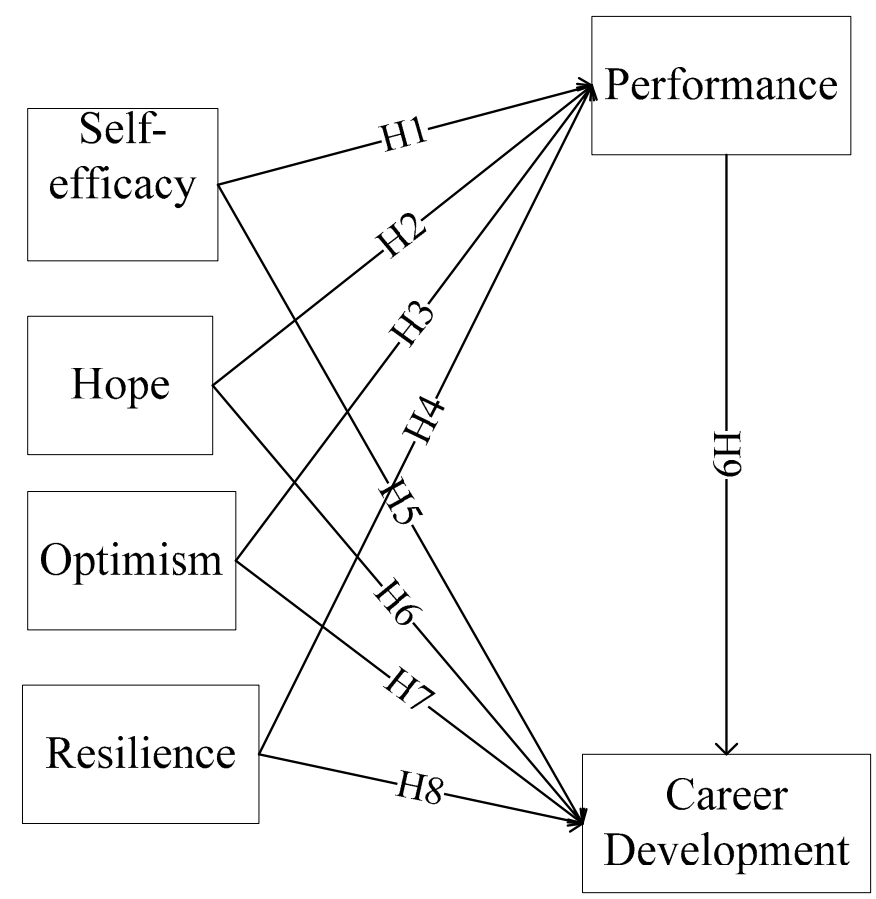

Figure 1. Hypothesis framework.

\section{Methods}

\subsection{Participants}

The study subjects were selected through cluster sampling of male players from 20 junior high school and 20 senior high school baseball teams around Taiwan. Following the school selection, the 
researcher made phone calls and explained the purpose of the study. With the schools' approval, the researcher sent survey questionnaires to each school and asked the coaches to give questionnaires to players to fill out the questionnaires and gatherer them back. Data were collected upon obtaining a clear consent agreement. A total of 800 questionnaires were distributed and 647 valid responses were retrieved, for a return rate of $80.9 \%$.

\subsection{Measurements}

The questionnaire was divided into four parts that included demographic variables, psychological capital scale, player performance scale, and career development scale.

\subsubsection{Demographic Variables}

Demographic variables included "education", "grade", "training time", and "fielding position".

\subsubsection{Psychological Capital Scale}

This study used a version of the PsyCap scale developed by Yang et al. [38] in which some phrases were modified to reflect the environment of young student athletes. The scale comprised four components: self-efficacy, hope, optimism, and resilience and all items were measured by a 5-point Likert scale ranging from 1 (strongly disagree) to 5 (strongly agree). Examples of the items are "I am confident in my motor skills", "I look forward to overcome the challenge from training", "I believe that I will become a great athlete", and "Despite difficulties, I can still keep up with the training".

\subsubsection{Player Performance Scale}

The player performance scale used in this study was based on that developed by Lin [39], and some phrases were modified according to the environment of young student athletes. The scale was comprised of 10 questions and consisted of two constructs: athletic ability and sport passion. The responses were measured using a five-point Likert scale ranging from 1 (strongly disagree) to 5 (strongly agree). Examples of the items are "During training, I am always aggressive and follow coaches' orders" and "I am passionate about baseball".

\subsubsection{Career Development Scale}

The career development scale used in this study was developed by Hung [40]. The scale consisted of 10 questions for two constructs: career exploration and career orientation. The 10 items were measured using a five-point Likert scale ranging from 1 (strongly disagree) to 5 (strongly agree). Examples of the items are "I know the connections between my interests and career choice" and "I am determined to become a professional baseball player".

\subsection{Data Analysis}

In this study, partial least squares-structural equation modeling (PLS-SEM) was used to test the hypotheses derived in the previous section. According to Chin [41], PLS-SEM benefits from (1) being distribution-free, (2) requiring only a small sample size, (3) having the ability to process multiple dependent and independent variables simultaneously, (4) handling collinearity, and (5) processing either formative or reflective indicators. Therefore, PLS-SEM was used to test the relationships in the study [42]. There are many statistical software packages that enable users to perform PLS-SEM analysis. In this study, we used Warp PLS version 5.0 statistical software (Laredo, TX, USA) developed by Kock [43] for data analysis. 


\section{Results}

\subsection{Profile and Characteristics of Study Respondents}

Of the 800 questionnaires distributed, 647 valid questionnaires were collected and processed. Table 1 presents the descriptive statistics of the participants. Among them, 298 were from junior high school students and 349 were from senior high school students. By grade level, 55 (8.5\%), 113 (17.5\%), $130(20.1 \%), 73(11.3 \%), 119(18.4 \%)$, and 157 (24.3\%) of respondents were in 7 th, 8 th, 9 th, 10th, 11th, and 12th grade, respectively. The length of training ranged from less than three years $(133 ; 20.6 \%)$, between 4 and 6 years $(296 ; 45.7 \%)$, 7-9 years $(188 ; 29.1 \%)$, and more than 10 years $(29 ; 4.5 \%)$. By fielding position, 198 (30.6\%), 379 (58.6\%), and 79 (10.8\%) were pitchers, fielders, and catchers, respectively.

Table 1. Demographic characteristics of the respondents $(\mathrm{N}=647)$.

\begin{tabular}{|c|c|c|c|c|c|}
\hline & Frequency & $\%$ & & Frequency & $\%$ \\
\hline Education & \multicolumn{5}{|c|}{ Training Experience } \\
\hline Junior high school & 298 & 46.1 & Under 3 years & 133 & 20.6 \\
\hline Senior high school & 349 & 53.9 & $4 \sim 6$ years & 296 & 45.7 \\
\hline Grade & & & $7 \sim 9$ years & 188 & 29.1 \\
\hline 7 th grade & 55 & 8.5 & & & \\
\hline 8 th grade & 113 & 17.5 & Over 10 years & 29 & 4.5 \\
\hline \multirow{2}{*}{ 9th grade } & \multirow{2}{*}{130} & \multirow{2}{*}{20.1} & Fielding position & & \\
\hline & & & pitcher & 198 & 30.6 \\
\hline 10th grade & 73 & 11.3 & infielder & 379 & 58.6 \\
\hline 11th grade & 119 & 18.4 & catcher & 70 & 10.8 \\
\hline 12 th grade & 157 & 24.3 & & & \\
\hline
\end{tabular}

\subsection{Structural Modeling and Hypothesis Testing}

The collected data were examined and used to test the hypotheses listed above using PLS-SEM. PLS-SEM analysis involves two analyses [44,45]: (1) confirmatory analysis (measurement model) to test the whether the measurements fit reliability and validity criteria for the structural modeling analysis and (2) path analysis (structural model) to test the significance of each hypothetical path model and calculate the value of each path coefficient.

\subsubsection{Measurement Model Results}

Convergent and discriminant validity were examined to test the validity of the instrument according to Hulland [46]. Composite reliability and Cronbach's $\alpha$ values for all scales exceeded the minimum threshold level of 0.70 [45], indicating the reliability of all scales used in the study (Table 1). For convergent validity, the square root of average variation extract (AVE) of all values exceeded the minimum threshold level of 0.70 , again indicating the reliability of all scales used in the study. Fornell and Larcker's test [47] for discriminant validity revealed that relatively high variances were extracted for each factor compared to the interscale correlations, which is an indicator of the discriminant validity of the six constructs (Table 2).

\subsubsection{Structural Model Results}

An evaluation of the structural model was used to examine the nine hypothesized relationships (Table 3 and Figure 2). Consistent with the value and significance of the path coefficients, all four PsyCap components appeared to have positive impacts on player performance (self-efficacy (SE; $\beta=0.13, p<0.05$ ), hope (HP; $\beta=0.25, p<0.05)$, optimism (OP; $\beta=0.23, p<0.05)$, and resilience (RS; $\beta=0.29, p<0.05))$. However, only SE $(\beta=0.17, p<0.05)$, OP $(\beta=0.17, p<0.05)$, and PP $(\beta=0.58$, $p<0.05)$ appeared to have positive impacts on career development of players. The explanatory power 
$\left(\mathrm{R}^{2}\right)$ of SE, HP, OP, and RS for players' performance was 0.65 and the value for player performance together with career development was 0.77 , indicating that the constructs proposed in this study were good predictors of the outcome variables.

Table 2. Reliability, convergent, and discriminant validity of the measurement model.

\begin{tabular}{ccccccccc}
\hline Construct & SE & HP & OP & RS & PP & CD & CR $^{\mathbf{b}}$ & $\boldsymbol{\alpha}^{\mathbf{c}}$ \\
\hline Self-efficacy (SE) & $0.819^{\mathrm{a}}$ & & & & & & 0.910 & 0.877 \\
Hope (HP) & 0.745 & $0.832^{\mathrm{a}}$ & & & & & 0.900 & 0.852 \\
Optimism (OP) & 0.718 & 0.743 & $0.848^{\mathrm{a}}$ & & & & 0.911 & 0.869 \\
Resilience (RS) & 0.723 & 0.720 & 0.697 & $0.812^{\mathrm{a}}$ & & & 0.906 & 0.870 \\
Player performance (PP) & 0.691 & 0.726 & 0.716 & 0.721 & $0.792^{\mathrm{a}}$ & & 0.931 & 0.915 \\
Career development (CD) & 0.707 & 0.685 & 0.721 & 0.686 & 0.835 & $0.820^{\text {a }}$ & 0.949 & 0.939 \\
\hline
\end{tabular}

Note: ${ }^{a}$ : Square root of AVE (average variance extracted); ${ }^{\text {}}$ : composite reliability; ${ }^{c}$ : Cronbach's alpha.

Table 3. Path results for the structural model.

\begin{tabular}{cccc}
\hline Hypothesis & Path & Path Coefficient $(\boldsymbol{\beta})$ & $p$-Value \\
\hline H1 & $\mathrm{SE} \rightarrow \mathrm{PP}$ & $0.13^{*}$ & $<0.05$ \\
H2 & $\mathrm{HP} \rightarrow \mathrm{PP}$ & $0.25^{*}$ & $<0.05$ \\
H3 & $\mathrm{OP} \rightarrow \mathrm{PP}$ & $0.23^{*}$ & $<0.05$ \\
H4 & $\mathrm{RS} \rightarrow \mathrm{PP}$ & $0.29^{*}$ & $<0.05$ \\
H5 & $\mathrm{SE} \rightarrow \mathrm{CD}$ & $0.17^{*}$ & $<0.05$ \\
H6 & $\mathrm{HP} \rightarrow \mathrm{CD}$ & $0.02^{*}$ & $>0.05$ \\
H7 & $\mathrm{OP} \rightarrow \mathrm{CD}$ & $0.17^{*}$ & $<0.05$ \\
H8 & $\mathrm{RS} \rightarrow \mathrm{CD}$ & $0.03^{*}$ & $>0.05$ \\
H9 & $\mathrm{PP} \rightarrow \mathrm{CD}$ & $0.58^{*}$ & $<0.05$ \\
\hline
\end{tabular}

*: significant; SE: self-efficacy; HP: hope; OP: optimism; RS: resilience; PP: player performance; CD: career development.

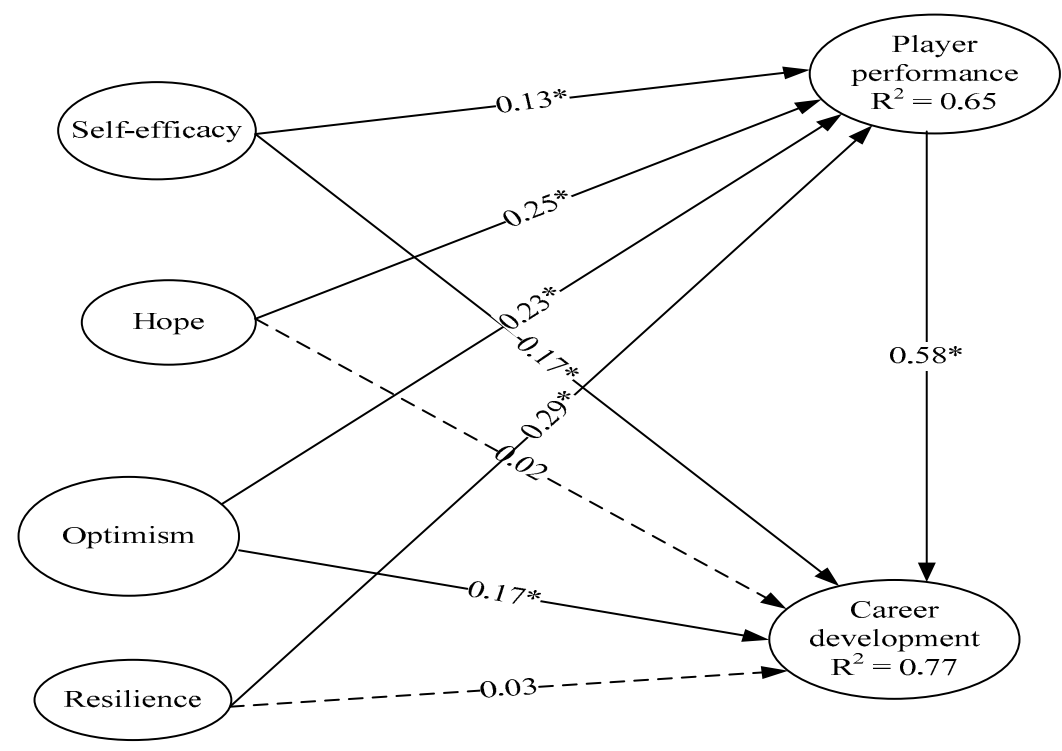

Figure 2. Standardized path coefficient estimated from the structural model. Note: dot line denotes significant; dash line denotes non-significant; $*$ : $p<0.05$. 


\section{Discussion}

\subsection{Relationship of PsyCap to Player Performance}

\subsubsection{Self-Efficacy and Player Performance}

Research findings revealed that the self-efficacy component of PsyCap in middle and high school baseball players had a positive impact on player performance $(\beta=0.13, p<0.05)$. These findings were consistent with previous studies that reported self-efficacy contributes to competitive player performance $[48,49]$. Self-efficacy is a major concept in social cognitive theory, which posits that individuals can be viewed as self-organizing, proactive, self-reflecting, and self-regulating [14]. Thus, self-efficacy influences the way an individual thinks and behaves, as well as their awareness. For athletes, self-efficacy can determine their willingness to overcome obstacles, make effort, and endure hardship. Previous studies reported that among senior high school tennis players, those who had higher self-efficacy were more likely to win in competitive games [50]. Moreover, Chi [51] pointed out that in highly competitive games, athletes who had higher self-efficacy could dominate by maintaining a positive mindset and increased focus. These athletes were more likely to implement effective game strategies.

According to Wang [52], athletes increase their self-efficacy and confidence through successive competitive successes. Based on studies of self-efficacy, Chan and Wang [53] suggest that athletic coaches can enhance the confidence of the athletes they train through self-comparison of measurements of effort and skill. In contrast, personal judgment, incentive systems, and internal competition can reduce the intrinsic motivation of athletes and should be avoided.

\subsubsection{Hope and Player Performance}

In this study we showed that hope can have positive influences on player performance $(\beta=0.25$, $p<0.05$ ). According to Curry and Snyder [30], hope is a vital component in an athletic competition, and those athletes who have lower levels of hope are less likely to maintain focus on overall goals. Goal-setting athletes tend to integrate their resources and create strategies, and those with high hope are more prepared in their ability to follow substitute plans when necessary. Those athletes who have low hope often cannot devise a game strategy, and have no backup plan if their initial plan is unsuccessful [54]. When equally competent players compete, the athlete that has high hope tends to perform better and can prepare himself/herself mentally to confront adversity [21]. Wang [52] also noted that hope in athletes can be built by maintaining a positive mindset and motivation. Therefore, athletes should be encouraged to write down and reprocess negative thoughts after games. By using these cognitive skills, they can better detect the flow of negative thought processes, realize how these processes affect them, and in turn regain energy and increase hope.

\subsubsection{Optimism and Player Performance}

Optimism was shown here to have a significant impact on player performance $(\beta=0.23, p<0.05)$. Luthans et al. [7] considered optimism as an explanatory style that attributes positive events to internal, pervasive, and permanent causes, and negative events to external, temporary, and situation-specific causes. Thus, optimism can usually be linked to psychological health outcomes. Optimistic individuals can quickly adjust themselves in the face of life obstacles and tackle problems. According to Tsai et al. [55], an optimistic attitude can contribute to positive emotions and hope. If athletes remain optimistic, they will believe that their goals are attainable and would be more willing to make more effort to achieve them [32]. To create a positive attitude, Wang [52] suggested that athletes facilitate self-forgiveness and accept past failures, mistakes, and setbacks. Furthermore, athletes should be encouraged to admire themselves and learn to appreciate their current athletic performance while continuing to aspire to be a better player. 


\subsubsection{Resilience and Player Performance}

Here we found that optimism had a significant impact on the performance of junior and senior high school baseball players $(\beta=0.29, p<0.05)$, which is consistent with findings from earlier studies [56]. Liu et al. [57] indicated that, in addition to athletic skill, mental toughness can help athletes rise to the top. Athletes with high resilience prepare themselves for competitions with energy and composure, and respond positively to challenges they face [58]. To enhance athletic performance, activities that increase psychological resilience and develop psychological skills should both be included in training programs [25]. As Wang [56] argued, development of resilience in athletes can be promoted by helping these athletes realize that the goal they set is achievable despite the trauma, stress, and challenges that may lie ahead. Strategies that help athletes overcome adversity and setbacks are, thus, important components of achieving high levels of athletic success.

\subsection{Psychological Capital, Player Performance and Career Development}

Both self-efficacy $(\beta=0.17, p<0.05)$ and optimism $(\beta=0.17, p<0.05)$ had significant positive impacts on career development of the study subjects, suggesting the beneficial effects of these two PsyCap factors in particular on the likelihood of an athlete to achieve a successful career.

A significant positive relationship was also found between player performance and career development $(\beta=0.58, p<0.05)$, which supports an earlier finding that, especially in sports, elite athletes have faith in their future career opportunities [59]. Ho et al. [60] discussed the occurrence of "brain drain" among athletes in Taiwan and that limited career choices can be a major problem for athletes. Highly competitive environments, limited competition opportunities, and lack of financial resources for teams are other potential constraints that can push young athletes away from pursuing an athletic career and toward other career opportunities. To encourage young baseball players to sustain long-term training, coaches can enhance athletes' PsyCap to improve competitive performance.

\section{Conclusions and Implications for Future Research}

\subsection{Conclusions}

This study examined the importance of PsyCap for the athletic performance and career development of high school baseball players. Our results showed that all four PsyCap components appeared to have positive influences on players' performance. In addition, self-efficacy and optimism of PsyCap and players' performance positively influenced players' career development.

\subsection{Suggestions}

This study found all four constructs of PsyCap had positive impacts on baseball players' performance. Among them, resilience of PsyCap had the highest influence on performance. It is, therefore, suggested for coaches to provide practical guidance for athletes to improve resilience aside from training. For example, coaches can help these athletes to meditate on the idea that the goals they set are achievable despite the trauma, stress, and challenges that may lie ahead. Strategies that help athletes overcome adversity and setbacks are, thus, important components of achieving high levels of athletic success.

As for career development, the study found self-efficacy and optimism of PsyCap and players' performance all have positive influences on players' career development. According to Wang [52], self-efficacy can be enhanced through the experiencing of success. Therefore, coaches are encouraged to cheer athletes after each training and winning, which will certainly build up their confidence and improve their self-efficacy. As for optimism, coaches can encourage athletes to appreciate their current athletic performance and keep up the good work which can direct them to become better players. 


\subsection{Limitations and Implications for Future Research}

This study focused on the baseball players' PsyCap effects of performance and career development. The study is one-sided since we did not touch the influences from coaches. Since coaches, schools, teachers, and peers together form a system that provides support to strengthen participation and success of young athletes. Thus, future studies should examine the effect of coaching leadership and support resources on the relationship between player performance and career development. In addition, since the study combined different stages of high school baseball players, namely, junior and senior high schools, it is, therefore, recommended to separate studies of junior high school players and senior high school players and that may provide valuable insights to understand whether PsyCap factors have varying effects on players at different education stages.

This study presents recommendations for future areas of research for young baseball players. Psychological capital and player performance are factors in career development and separate studies of junior high school players and senior high school players would be valuable to understand whether PsyCap factors have varying effects on players at different education stages.

Author Contributions: Data curation, C.-P.L. and F.-T.N.; formal analysis, C.-M.C.; investigation, F.-T.N. and C.-M.C.; project administration, C.-M.C.; resources, C.-P.L. and H.-H.H.; writing-review and editing, C.-M.C. and H.-H.H. All authors have read and agreed to the published version of the manuscript.

Funding: The authors received no specific funding for this work.

Acknowledgments: We would like to thank all respondents for the survey. We would like to thank the three anonymous reviewers for providing thorough insightful suggestions and comments.

Conflicts of Interest: The authors declare that they have no conflict of interest regarding the publication of this paper.

\section{References}

1. Lin, H.W. A Study of Taiwanese Professional Baseball; Sports Affairs Council, Executive Yuan: Taipei, Taiwan, 2000.

2. Kellner, S. Taking it to the Limit with Basketball Cybernetics; Stan Kellner: East Setauket, NY, USA, 1989.

3. Williams, J.M.; Krane, V. Psychological characteristics of peak performance. In Applied Sport Psychology: Personal Growth to Peak Performance; Williams, J.M., Ed.; Mayfield Publishing Company: Mountain View, CA, USA, 2001; pp. 162-178.

4. Weinberg, R.S. The Mental Advantage: Developing Your Psychological Skills in Tennis; Human Kinetics: Champaign, IL, USA, 1988.

5. Avey, J.B.; Luthans, F.; Mhatre, K.H. A call longitudinal research in positive organizational behavior. J. Organ. Behav. 2008, 29, 705-711.

6. Luthans, F.; Luthans, K.W.; Luthans, B.C. Positive psychological capital: Beyond human and social capital. Bus. Horiz. 2004, 47, 45-50. [CrossRef]

7. Schaufeli, W.B.; Bakker, A.B. Job demands, job resources, and their relationship with burnout and engagement: A multi-sample study. J. Organ. Behav. 2004, 25, 293-315.

8. Peterson, S.J.; Luthans, F.; Avolio, B.J.; Walumbwa, F.O.; Zhang, Z. Psychological capital and employee performance: A latent growth modeling approach. Pers. Psychol. 2011, 64, 427-450.

9. Sweetman, D.; Luthans, F.; Avey, J.B.; Luthans, B.C. Relationship between positive psychological capital and creative performance. Can. J. Adm. Sci. 2011, 28, 4-13.

10. Byars, L.L.; Rue, L.W. Human Resource Management; Richard, D., Ed.; Irwin Inc.: Homewood, IL, USA, 1994.

11. Montross, D.H.; Shinkman, C.J. Career Development: Theory E Practice; Charles C Thomas Publisher: Springfield, IL, USA, 1992.

12. Liu, Z.C.; Chen, Y.C.; Huang, T.S. Professional player compensation and its impact factor analysis-Comparative study of professional baseball leagues in Korea, Japan, Taiwan, and the United States. Leis. Ind. Res. 2009, 7, 87-105.

13. Kang, C.N.; Juang, L.G.; Kan, S.P.; Wang, H.K. A descriptive epidemiological study of sports injury in high school baseball players. Formos. J. Phys. Ther. 2005, 30, 217-222. 
14. Bandura, A. Self-efficacy: Toward a unifying theory of behavioral change. Psychol. Rev. 1977, 84, $191-215$. [CrossRef]

15. Bandura, A. Social Foundations of Thought and Action: A Social Cognitive Theory; Prentice-Hall: Englewood Cliffs, NJ, USA, 1986.

16. Bandura, A. Self-Efficacy: The Exercise of Control; W. H. Freeman: New York, NY, USA, 1997.

17. American Psychological Association. Teaching Tip Sheet: Self-Efficacy. Available online: https://www.apa. org/pi/aids/resources/education/self-efficacy (accessed on 13 February 2020).

18. Snyder, C.R.; Harris, C.; Anderson, J.R.; Holleran, S.A.; Irving, L.M.; Sigmon, S.T.; Yoshinobu, L.; Gibb, J.; Laugelle, C.; Harney, P. The will and the ways: Development and validation of an individual differences measure of hope. J. Personal. Soc. Psychol. 1991, 60, 570-585. [CrossRef]

19. Luthans, F.; Youssef, C.M.; Avolio, B.J. Psychological Capital; Oxford University Press: Oxford, UK, 2007.

20. Masten, A.S. Ordinary magic: Resilience processes in development. Am. Psychol. 2001, 56, $227-239$. [CrossRef]

21. Ni, F.T.; Tseng, M.H.; Chen, W.C.; Chang, C.M. The effects of psychology capital on sports achievement of badminton athletes in universities. J. Sport Recreat. Manag. 2015, 12, 30-46. [CrossRef]

22. Lee, C.L.; Chang, W.C.; Hsu, C.H.; Ho, P.Y. The influences of study of psychological capital to sports performance in wrestler. J. Sport Recreat. Res. 2017, 12, 106-115. [CrossRef]

23. Chen, C.W.; Chi, L.K. The prediction of $2 \times 2$ goal orientations and hope on stress coping strategies among college athletes. Phys. Educ. J. 2009, 42, 71-86. [CrossRef]

24. Hsieh, W.S.; Yeh, L.C. The study of positive mentality, exercise self-efficacy, and exercise behavior. J. Phys. Educ. Fu Jen Cathol. Univ. 2008, 7, 105-121. [CrossRef]

25. Huang, C.J. Establishing the Construct of Mental Toughness for Sport: Preliminary Investigation and Instrument Development. Ph.D. Thesis, National Taiwan Normal University, Taiwan, 2003.

26. Locke, E.A.; Latham, G.P. Building a practically useful theory of goal setting and task motivation. Am. Psychol. J. 2002, 57, 705-717. [CrossRef]

27. Yu, M.C.; Chen, W.C.; Hung, C.C. The effects of positive psychological capital, work engagement, and service climate on service-oriented organizational citizenship behavior: The case of telecommunications industry. Serv. Ind. Manag. Rev. 2014, 11, 25-42.

28. Niles, S.G.; Sowa, C.J. Mapping the nomological network of career self -efficacy. Career Dev. Q. 1992, 41, 13-21. [CrossRef]

29. Arbona, C. Practice and research in career counseling and development-1999. Career Dev. Q. 2000, 49, 98-134. [CrossRef]

30. Curry, L.A.; Snyder, C.R. Hope takes the field: Mind matters in athletic performances. In Handbook of Hope: Theory, Measures, and Applications; Snyder, C.R., Ed.; Academic Press: San Diego, CA, USA, 2000; pp. 243-260.

31. Snyder, C.R. Hope theory: Rainbow in the mind. J. Psychol. Inq. 2002, 13, 249-275. [CrossRef]

32. Scheier, M.; Carver, C. Dispositional optimism and physical well-being: The influence of generalized outcome experiences on health. J. Pers. 1987, 55, 169-210. [CrossRef]

33. Lin, Y.C. An empirical study on sport resilience. Q. Chin. Phys. Educ. 2011, 25, 509-517. [CrossRef]

34. Loehr, L.E. Athletic Excellence: Mental Toughness Training for Sports; Plome: New York, NY, USA, 1982.

35. Chan, C.C.; Chen, S.C. The practicable strategies of athletes career counseling. Q. Chin. Phys. Educ. 2013, 27, 31-38. [CrossRef]

36. Wang, C.C.; Yeh, S.T.; Chen, C.C. Explore of athletes' college enrollment channels in senior high schools. Ncyu J. Phys. Educ. Health Recreat. 2011, 10, 229-236. [CrossRef]

37. Chan, C.C. An Investigation Study on the Senior High School Athletic Classes in Taiwan Area. Master's Thesis, National Taiwan Sport University, Taiwan, 2003.

38. Yang, H.W.; Lin, T.L.; Ho, P.T.; Yang, H.F. The relationship between psychological capital and sport burnout of physical education students in junior high schools. Ncyu J. Phys. Educ. Health Recreat. 2013, 12, 40-52. [CrossRef]

39. Lin, W.B. Measuring pitchers' performance using data envelopment analysis. Sports Exerc. Res. 2004, 6, 119-131. [CrossRef]

40. Hung, H.C. The influence of social support and career belief toward the career development of high school students of the department of physical education. J. Natl. Cheng K. Univ. Phys. Educ. Res. 2012, 44, 17-33. [CrossRef] 
41. Chin, W.W. The partial least squares approach for structural equation modeling. In Modern Methods for Business Research; Marcoulides, G.A., Ed.; Lawrence Erlbaum Associates: Mahwah, NJ, USA, 1998; pp. 295-336.

42. Vinzi, E.; Chin, V.W.W.; Henseler, J.; Wang, H. Handbook of Partial Least Squares: Concepts, Methods And Applications; Springer Handbooks of Computational Statistics Series; Springer: Heidelberg, Germany; Dordrecht, The Netherlands; London, UK; New York, NY, USA, 2010; Volume II, Available online: https: //www.smartpls.com/documentation/literature/books (accessed on 23 April 2017).

43. Kock, N. WarpPLS 5.0 User Manual; Script Warp Systems: Laredo, TX, USA, 2015.

44. Pirouz, D.M. An Overview of Partial Least Squares. 2006. Available online: http://ssrn.com/abstract=1631359 (accessed on 26 February 2018).

45. Hair, J.F.; Hult, G.T.M.; Ringle, C.M.; Sarstedt, M. A Primer on Partial Least Squares Structural Equation Modeling (Pls-Sem), 2nd ed.; Sage: Thousand Oaks, CA, USA, 2017.

46. Hulland, J. Use of partial least squares (PLS) in strategic management research: A review of four recent studies. Strat. Manag. J. 1999, 20, 195-204. [CrossRef]

47. Fornell, C.; Larcker, D.F. Evaluating structural equation models with unobservable variables and measurement error. J. Mark. Res. 1981, 18, 39-50. [CrossRef]

48. Chang, Y.K.; Yen, S.H. Explore the mental toughness on the situation of sports. Q. Chin. Phys. Educ. 2011, 25, 499-508. [CrossRef]

49. Sivrikaya, M.H. The role of self-efficacy on performance of sports skills of football players. J. Educ. Train. Stud. 2019, 6, 75-79. [CrossRef]

50. Caserta, R.J. Sport-Confidence as Related to Performance in Male and Female Tennis Players. Master's Thesis, Springfield College, Springfield, MA, USA, 2002.

51. Chi, L.K. A good way to build self-confidence. Chin. Baseb. 1996, 55, 83-85.

52. Wang, J.X. Analysis of psychological capital value of excellent athletes and intervention strategies. J. Sports Adult Educ. 2010, 26, 56-59.

53. Chan, H.W.; Wang, H.Y. Exploration on the confidence theory and self-confidence. J. Phys. Educ. Natl. Taichung Univ. 2010, 5, 35-40. [CrossRef]

54. Gustafsson, H.; Hassmén, P.; Podlog, L. Exploring the relationship between hope and burnout in competitive sport. J. Sports Sci. 2010, 28, 1495-1504. [CrossRef] [PubMed]

55. Tsai, W.H.; Su, H.T.; Chou, W.H. Exploration on the relationship between positive state of mind and the recreational sports. J. Sport Commun. 2010, 3, 91-105. [CrossRef]

56. Gould, D.; Hodge, K.; Peterson, K.; Petlichkoff, L. Psychological foundations of coaching: Similarities and differences among intercollegiate wrestling coaches. Sport Psychol. 1987, 1, 293-308. [CrossRef]

57. Liu, C.H.; Lin, R.Y.; Yu, C.S.; Hong, T.K.; Lin, T.M. Research on the effect of mental skill training mental toughness and perseverance skill performance of athletes. J. Phys. Educ. Sport Sci. 2007, 5, 59-66. [CrossRef]

58. Fang, T.H. Mental toughness among senior high school soft tennis players. Taipei Phys. Educ. Coll. J. 2009, 18, 13-23. [CrossRef]

59. Hong, C.W.; Chan, C.C. Current development and future outlook of high school physical education class. $Q$. Chin. Phys. Educ. 2005, 19, 63-71. [CrossRef]

60. Ho, Y.M.; Chang, T.C.; Ho, G.L.; Chen, H.Q. A study of influential factors for lost baseball players. Taipei Phys. Educ. Coll. J. 2008, 16, 248-260. [CrossRef]

(C) 2020 by the authors. Licensee MDPI, Basel, Switzerland. This article is an open access article distributed under the terms and conditions of the Creative Commons Attribution (CC BY) license (http://creativecommons.org/licenses/by/4.0/). 